\title{
Correction to: Image deblurring based on enhanced salient edge selection
}

\author{
Dandan $\mathrm{Hu}^{1} \cdot$ Jieqing $\operatorname{Tan}^{1,2} \cdot \mathrm{Li} \mathrm{Zhang}^{1} \cdot$ Xianyu Ge${ }^{2}$
}

Published online: 10 January 2022

๑) Springer-Verlag GmbH Germany, part of Springer Nature 2021

\section{Correction to:}

The Visual Computer

https://doi.org/10.1007/s00371-021-02329-6

Dear Readers,

Unfortunately, some text passages with minor spelling errors were published in the original version of this article.

We apologize for this and refer to the published correction.

"The original article has been corrected."

Publisher's Note Springer Nature remains neutral with regard to jurisdictional claims in published maps and institutional affiliations.

The original article can be found online at https://doi.org/10.1007/ s00371-021-02329-6.

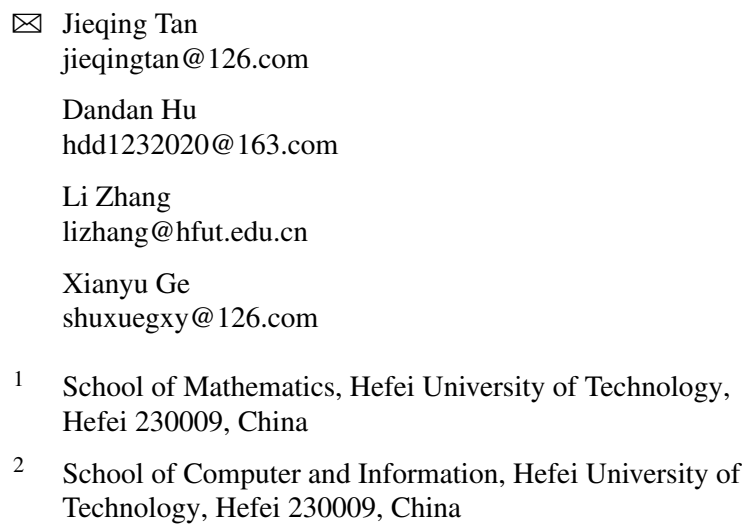

1 School of Mathematics, Hefei University of Technology, Hefei 230009, China

2 School of Computer and Information, Hefei University of Technology, Hefei 230009, China 